\title{
Atomic Layer Deposition of Magnetic Thin Films
}

\author{
R. Mantovan ${ }^{a}$, M. Georgieva ${ }^{a}$, M. Perego ${ }^{a}$, H.L. Lu ${ }^{a}$,
}

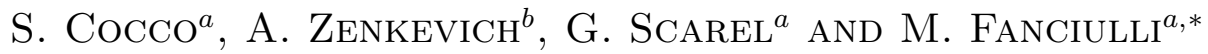

${ }^{a}$ Laboratorio Nazionale MDM CNR-INFM

via C. Olivetti 2, Agrate Brianza I-20041, Italy

${ }^{b}$ Moscow Engineering Physics Institute, 115409 Moscow, Russia

We report on the research effort towards the development of processes for the realization of magnetic tunnel junctions by atomic layer deposition. Our strategy follows two main schemes. The first is a hybrid process where the ferromagnetic layers are produced by chemical vapour deposition and the tunnel oxide is deposited by atomic layer deposition. As ferromagnetic electrodes we use Co and $\mathrm{Fe}_{3} \mathrm{O}_{4}$, while $\mathrm{MgO}, \mathrm{Al}_{2} \mathrm{O}_{3}$, and $\mathrm{HfO}_{2}$ are employed as tunnel oxides. The second and most intriguing scheme is a full-oxide approach in which the ferromagnetic layers and the tunnel barrier layer are all oxides grown by atomic layer deposition. As ferromagnetic layers we focused on the growth of complex manganites $\left(\mathrm{La}_{0.7} \mathrm{Sr}_{0.3} \mathrm{MnO}_{3}\right)$ while as a tunnel oxide we propose $\mathrm{La}_{2} \mathrm{O}_{3}$. Film composition has been studied with time of flight secondary ion mass spectroscopy and Rutherford backscattering spectrometry. X-ray diffraction, X-ray reflectivity, and Fourier transform infrared spectroscopy have been used to investigate the structure and morphology of the layers. The magnetic properties of the films are measured by superconducting quantum interference device magnetometer.

PACS numbers: 81.15.- $\mathrm{z}, 75.70 .-\mathrm{i}$

\section{Introduction}

Magnetic tunnel junctions (MTJs) are the fundamental storage elements in magnetic random access memory. A MTJ consists of two ferromagnetic (FM) layers separated by an ultrathin insulating layer, with a thickness of a few nanometers. The tunneling current in MTJ depends on the relative orientation of magnetizations of the two FM layers, which can be changed by an applied magnetic field. Nowadays, MTJs are based mostly on transition-metal FM electrodes and $\mathrm{Al}_{2} \mathrm{O}_{3}$ barriers. These can be fabricated with reproducible characteristics and with tunnel

*corresponding author; e-mail: marco.fanciulli@mdm.infm.it 
magnetoresistance (TMR) values up to $70 \%$ at room temperature (RT). Recently, $\mathrm{TMR}>200 \%$ at RT has been observed in epitaxial MTJ based on Fe and $\mathrm{MgO}[1,2]$.

The increasing interest in this field motivates the development of efficient and cost-effective methods capable of growing smooth, uniform, and conformal FM layers. Atomic layer deposition (ALD) is an efficient deposition method to grow materials with the above-mentioned structural characteristics, moreover, the ALD process can be easily transferred to industrial lines and it is already used for growing of high- $\kappa$ dielectrics in ultra-scaled complementary metal-oxide-semiconductor (CMOS) devices. In ALD, the deposition occurs through self-limiting chemical reactions, promoting the formation of films with smooth surface. A good chemical quality of the deposited layers, and chemical stability between two layers of different nature are expected [3]. ALD is a powerful method for the deposition of binary and more complex oxides. On the contrary, the growth of metals such as Co or Fe by ALD is a difficult and dangerous process making use of hydrogen [4].

In this paper we present our research effort for producing MTJ with an ALDbased process following two main schemes. The first is a hybrid process where the FM layers (Co and $\mathrm{Fe}_{3} \mathrm{O}_{4}$ ) are produced by chemical vapour deposition (CVD) and the tunnel oxide $\left(\mathrm{Al}_{2} \mathrm{O}_{3}, \mathrm{HfO}_{2}\right.$, or $\mathrm{MgO}$ ) is deposited by ALD. $\mathrm{Fe}_{3} \mathrm{O}_{4}$ (magnetite) has attracted a great interest as a possible FM electrode for MTJ, since it should show half-metallic properties with a Curie temperature $\left(T_{\mathrm{C}}\right)$ of about $850 \mathrm{~K}[5]$. The second and most intriguing scheme for producing MTJ by ALD is a full-oxide approach in which the FM layers and the tunnel barrier layer are all oxides deposited in the ALD reactor. As FM oxides we focused on complex manganites such as $\mathrm{La}_{1-x} \mathrm{Sr}_{x} \mathrm{MnO}_{3}$ (LSMO), while as a tunnel oxide we propose to use $\mathrm{La}_{2} \mathrm{O}_{3}$. The LSMO films belong to the class of half-metallic materials. In general, the magnetic oxide materials of the perovskites type $\mathrm{La}_{1-x}^{3+} \mathrm{A}_{x}^{2+} \mathrm{MnO}_{3}$, where $\mathrm{A}$ is a divalent alkaline metal $(\mathrm{Sr}, \mathrm{Ca}, \mathrm{Ba}, \mathrm{Pb})$, have been studied extensively due to their potential application in the field of spintronics [6], having a possible application as FM electrodes in MTJ devices [7]. The best magnetic properties in the LSMO system are reported for the $\mathrm{La}_{0.67} \mathrm{Sr}_{0.33} \mathrm{MnO}_{3}$ compound $\left(T_{\mathrm{C}} \sim 370 \mathrm{~K}\right)$. The most common techniques for the LSMO films depositions are molecular beam epitaxy, pulsed laser deposition, and sputtering from targets with the exact desired composition $[8,9]$. All these techniques have been successful in producing good quality films, although they are limited by small substrate sizes, insufficient compositional control over larger areas, and a high cost. We believe that the ALD could give an alternative to the above-mentioned deposition techniques combined with a low cost and the ability to deposit material conformally over large areas and with low compositional variations. Indeed, ALD has been successfully used to grow $\mathrm{La}_{1-x} \mathrm{Ca}_{x} \mathrm{MnO}_{3}$ films [10], although the growth by ALD of epitaxial layers remains a challenging objective.

In this contribution, we discuss the structural and magnetic properties of the FM layers and oxide films deposited by ALD and CVD methods. 


\section{Experimental}

The $\mathrm{Al}_{2} \mathrm{O}_{3}, \mathrm{HfO}_{2}, \mathrm{MgO}$, LSMO, and $\mathrm{La}_{2} \mathrm{O}_{3}$ films have been grown by ALD in a F-120 ASM-Microchemistry reactor. The binary oxides have been grown on Si substrates, and conventional HF-last cleaning has been used to remove the native oxide. The $\mathrm{Al}_{2} \mathrm{O}_{3}, \mathrm{HfO}_{2}$, and $\mathrm{MgO}$ oxide layers have been deposited from $\mathrm{Al}\left(\mathrm{CH}_{3}\right)_{3}, \mathrm{HfCl}_{4}$, and $\mathrm{Mg}\left(\mathrm{C}_{5} \mathrm{H}_{5}\right)_{2}$ precursors respectively, in combination with $\mathrm{H}_{2} \mathrm{O}$ as oxygen source. We have focused our attention on the growth of $\mathrm{MgO}$. The $\mathrm{MgO}$ films have been grown on $\mathrm{p}-\mathrm{Si}(100)$ substrates at 225,300 , and $375^{\circ} \mathrm{C}$. The complex quaternary manganites have been grown on thermally oxidized $\mathrm{Si}$ substrates in a $200-500^{\circ} \mathrm{C}$ temperature range, by combining the $\left(\mathrm{C}_{11} \mathrm{H}_{19} \mathrm{O}_{2}\right)$ type of ligands for $\mathrm{La}^{3+}, \mathrm{Sr}^{2+}$, and $\mathrm{Mn}^{3+}$ cations and by using $\mathrm{O}_{3}$ as an oxygen source. Following the work of Nilsen [10] on LaCaMnO films, as a starting step we have deposited LaSrMnO films at two different growth temperatures, $283^{\circ} \mathrm{C}$ and $450^{\circ} \mathrm{C}$.

The $\mathrm{Co}$ and $\mathrm{Fe}_{3} \mathrm{O}_{4}$ magnetic films have been grown on $\mathrm{Si} / \mathrm{SiO}_{2}(550 \mathrm{~nm})$ substrates via a CVD process, by using a very simple and low cost laboratory set-up. The $\mathrm{Si} / \mathrm{SiO}_{2}$ substrates (area $\sim 2 \times 2 \mathrm{~cm}^{2}$ ) can be accommodated both vertically and horizontally in a quartz tube inside a standard furnace used for slow-ramp thermal annealing. A bubbler system containing the precursor is sealed to one side of the quartz tube, and a vacuum pump is connected to the other side. For the Co films deposition, a di-cobalt octacarbonyl precursor $\mathrm{Co}_{2}(\mathrm{CO})_{8}$ kept at $\mathrm{RT}$ is used. The $2 \mathrm{Co}_{2}(\mathrm{CO})_{8} \rightarrow 4 \mathrm{Co}+16 \mathrm{CO}$ reaction is induced by working below the precursor vapour pressure $(\sim 0.1 \mathrm{mbar}$ at RT). Such a condition can be easily achieved by using a standard rough pumping system. Our method is similar to that described in Ref. [11]. The growth of the Co films is possible with and without carrier gas ( $\mathrm{Ar}$ or forming gas, $\mathrm{N}_{2}+4 \% \mathrm{H}_{2}$ ). Co films with various thicknesses $(30-80 \mathrm{~nm})$ are deposited by heating the substrate in the $90-200^{\circ} \mathrm{C}$ temperature range. Grow rates in the $2-40 \mathrm{~nm} / \mathrm{min}$ range are obtained. The $\mathrm{Fe}_{3} \mathrm{O}_{4}$ thin films have been deposited by using a tri-iron dodecarbonyl $\mathrm{Fe}_{3}(\mathrm{CO})_{12}$ precursor, in the same experimental set-up used for growing the Co films. $\mathrm{Fe}_{3} \mathrm{O}_{4}$ magnetic films in the $30-60 \mathrm{~nm}$ range can be deposited by making use of both $\mathrm{Ar}$ and forming carrier gas. The substrate temperature is in a $200-400^{\circ} \mathrm{C}$ range.

Film composition has been studied with time of flight secondary ion mass spectroscopy (ToF-SIMS) and Rutherford backscattering spectrometry (RBS). ToF-SIMS measurements have been performed on a dual beam IONTOF IV instrument using $\mathrm{Ga}^{+}$ions at $25 \mathrm{keV}$ for analysis and $\mathrm{Cs}^{+}$ions at $1 \mathrm{keV}$ for sputtering. Data have been acquired in negative polarity, rastering the $\mathrm{Cs}^{+}$ion beam over a $200 \times 200 \mu \mathrm{m}^{2}$ area and the $\mathrm{Ga}^{+}$ion beam over a $50 \times 50 \mu \mathrm{m}^{2}$ area. No depth scale calibration has been performed. RBS analysis has been completed by using an $\mathrm{He}^{+}$ions beam with the incident energy $E_{0}=1.5 \mathrm{MeV}$ at the scattering geometry $\theta=160^{\circ}$.

Grazing incidence X-ray diffraction (GIXRD) and X-ray reflectivity (XRR) spectra have been acquired from a laboratory set-up equipped with a sealed 
X-ray tube, multilayer monochromator selecting a parallel beam of $\mathrm{Cu} K_{\alpha}$ radiation and a system of crossed slits defining a beam of appropriate size. XRR spectra have been collected from a scintillator detector and the GIXRD spectra have been recorded with a position sensitive detector (Inel CPS120).

Fourier transform infrared spectroscopy (FTIR) has been performed with a Bruker IFS66v/s spectrometer operating in a 1.0 mbar vacuum to remove air-related absorption bands. All samples have been probed by using the transmission geometry at either normal $\left(\theta=0^{\circ}\right)$ or grazing $\left(\theta=70^{\circ}\right)$ incidence, in order to detect both the transverse optical mode (TO) and the longitudinal optical mode (LO).

The magnetic properties of the deposited films, have been investigated by using the quantum design magnetic property measurements system (MPMS) magnetometer employing superconducting quantum interference device (SQUID) as a detector of the magnetic moment. All hysteresis loops have been measured at RT and in a broad range of magnetic fields up to $5 \mathrm{~T}$.

\section{Results and discussion}

3.1. Hybrid process (CVD and $A L D$ ) for MTJ

The ToF-SIMS profile of the as-deposited Co film is presented in Fig. 1a. The very low intensity of the $\mathrm{CoO}$ signal clearly indicates that the deposited film is composed by metallic cobalt. The high intensity of the $\mathrm{CoO}$ signal in the near surface region indicates the presence of a very thin cobalt oxide on top of the metallic film. This thin cobalt oxide film is clearly related to cobalt oxidation during exposition to air.

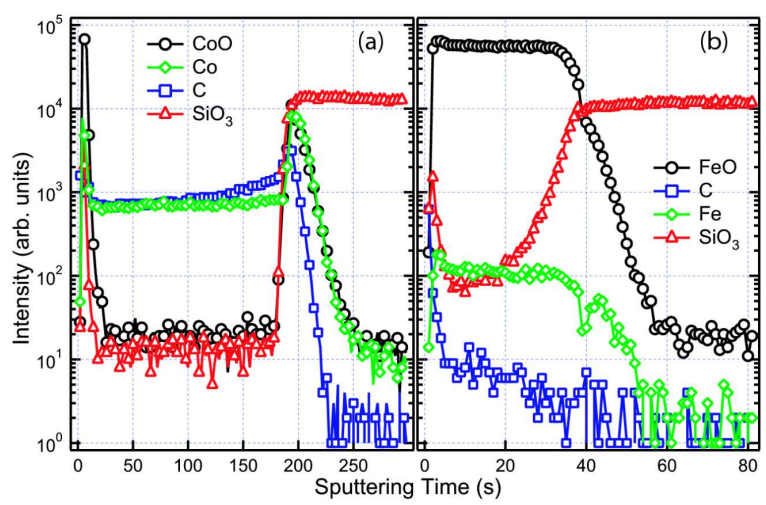

Fig. 1. ToF-SIMS depth profiles of the as-deposited (a) Co and (b) $\mathrm{Fe}_{3} \mathrm{O}_{4}$ samples.

According to XRD results, the as-deposited Co layers are amorphous or polycrystalline depending on the deposition conditions and the film thickness. From the fits of the XRR spectra, the film thickness, roughness, and electronic density are obtained. A typical XRR for one of the Co films is shown in Fig. 2a. The 
critical edge, directly connected to the electronic density of the film, is obtained from the fits and coincides well with the one for a pure Co film which evidences a good quality, the pure Co film with only one thin native oxide layer on top. The film roughness is still higher than the desirable one being around $10 \%$ of the film thickness.
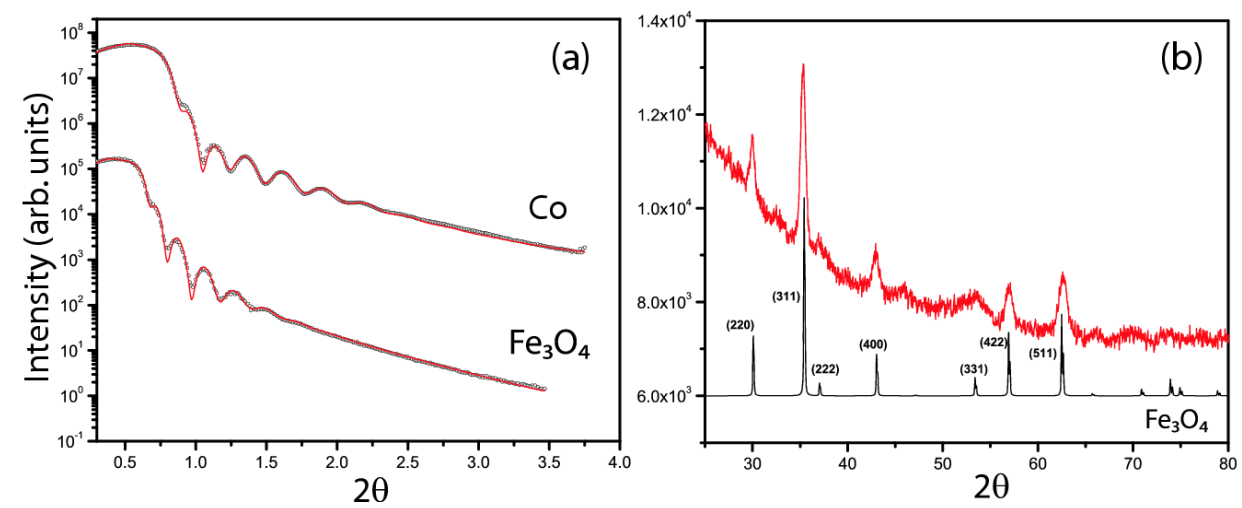

Fig. 2. (a) XRR spectra of $\mathrm{Co}$ and $\mathrm{Fe}_{3} \mathrm{O}_{4}$ films grown with the CVD method on the $\mathrm{Si} / \mathrm{SiO}_{2}$ substrates; (b) GIXRD of a $35 \mathrm{~nm}$ thick $\mathrm{Fe}_{3} \mathrm{O}_{4}$ film.

The magnetic hysteresis loop at RT for a sample deposited at $200^{\circ} \mathrm{C}$ is shown in Fig. 3a. It is apparent that the Co film is magnetically very soft $\left(H_{\mathrm{C}}=9 \mathrm{Oe}\right)$. The sample is easily saturated in low magnetic fields with a saturation magnetization slightly lower $(\sim 1200 \mathrm{emu} / \mathrm{cc})$ from the one expected for a bulk Co, $1400 \mathrm{emu} / \mathrm{cc}$. However, the value that we have obtained for the saturation magnetization of the as-deposited Co films is higher than the saturation magnetization obtained for Co with a similar deposition method and previously reported in the literature [12].

Figure $2 \mathrm{~b}$ shows the XRD spectra of a $35 \mathrm{~nm}$ thick $\mathrm{Fe}_{3} \mathrm{O}_{4}$ film grown at $300^{\circ} \mathrm{C}$ with Ar carrier gas, with the precursor kept at RT. The observed phase correspond to the $\mathrm{Fe}_{3} \mathrm{O}_{4} \mathrm{Fd} 3 \mathrm{~m}$ cubic structure. Figure $1 \mathrm{~b}$ reports the ToF-SIMS profile of the as-deposited $\mathrm{Fe}_{3} \mathrm{O}_{4}$ sample. The $\mathrm{FeO}$ and $\mathrm{Fe}$ signals are constant throughout the profile indicating that the film is homogeneous. Carbon contaminations are below the sensitivity limits of the instrument. The hysteresis loop at RT of the above-mentioned $\mathrm{Fe}_{3} \mathrm{O}_{4}$ film is shown in Fig. 3b. The film has a coercivity of 330 Oe which is significantly different from that of the Co films obtained here. This makes it a good candidate as a hard magnetic electrode in a potential MTJ device structure. The saturation magnetization value is about the same as the one expected for a pure $\mathrm{Fe}_{3} \mathrm{O}_{4}$ film at RT and it is around $465 \mathrm{emu} / \mathrm{cc}$.

As prospective tunnel oxides, we have focused our attention on $\mathrm{Al}_{2} \mathrm{O}_{3}, \mathrm{HfO}_{2}$, and $\mathrm{MgO}$. The electrical and structural properties of $\mathrm{Al}_{2} \mathrm{O}_{3}$ and $\mathrm{HfO}_{2}$ deposited by ALD are well documented [13-15], and $\mathrm{MgO}$ has also been successfully produced 

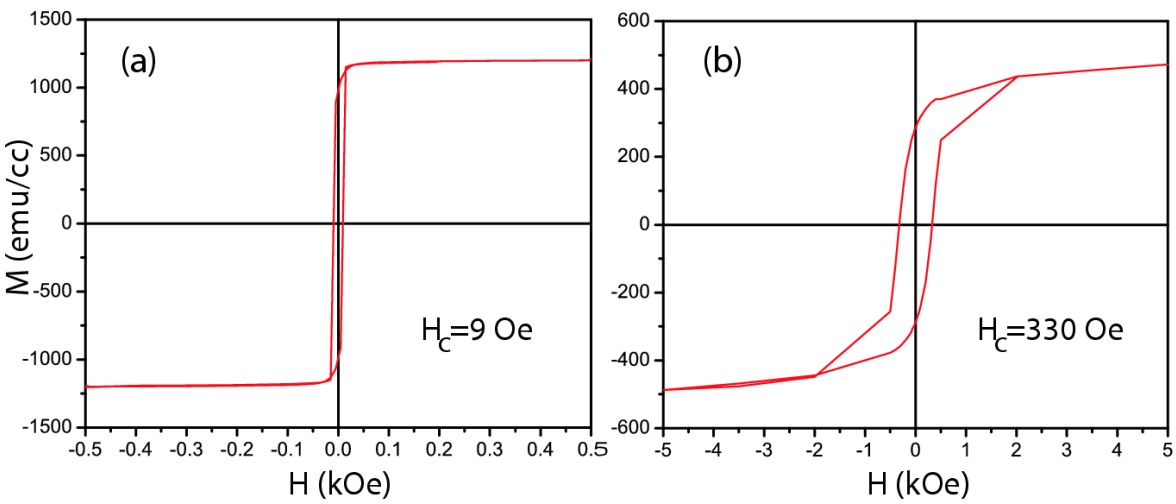

Fig. 3. Magnetic hysteresis loops measured at RT for (a) Co film, (b) $\mathrm{Fe}_{3} \mathrm{O}_{4}$ film, both deposited with the CVD method.
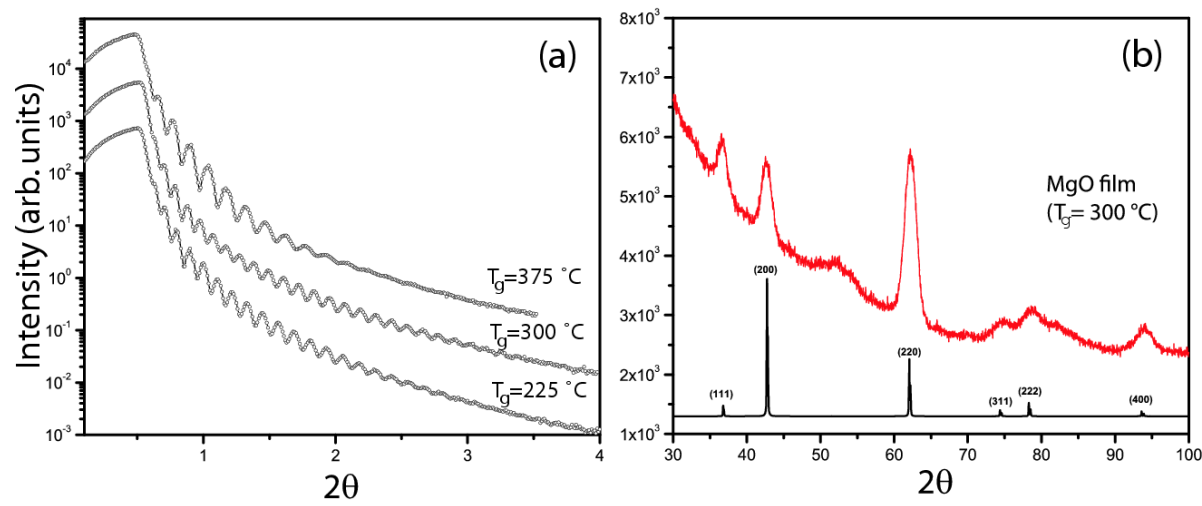

Fig. 4. (a) XRR and (b) XRD spectra of the MgO films deposited by ALD at different temperatures.

by ALD [16]. The MgO films that we have deposited by ALD are found to be polycrystalline with the crystal phase corresponding to $F m 3 m$ cubic. The XRD spectrum of the sample grown at $300^{\circ} \mathrm{C}$ is given in Fig. $4 \mathrm{~b}$. All the as-grown films have a preferential orientation along the (110) crystallographic direction. The $\mathrm{XRR}$ spectra for the $\mathrm{MgO}$ films grown at three different temperatures are shown in Fig. 4a. The calculated electronic density is in good agreement with the one obtained for bulk $\mathrm{MgO}$. The film thicknesses are about the same for samples grown at $225^{\circ} \mathrm{C}$ and $300^{\circ} \mathrm{C}$, being around $70 \mathrm{~nm}$. The film grown at higher temperature $375^{\circ} \mathrm{C}$ has a significantly lower thickness of about $55 \mathrm{~nm}$. This could be due to the change of the precursor decomposition rate at high temperatures. The roughness extracted from the data fits is about $4 \%$ of the film thickness, i.e the films grown at $300^{\circ} \mathrm{C}$ have a thickness of $71 \mathrm{~nm}$ and $3 \mathrm{~nm}$ roughness. The surface physical roughness of $\mathrm{MgO}$ films deposited by ALD is expected to decrease with the thickness of the deposited films [16]. 


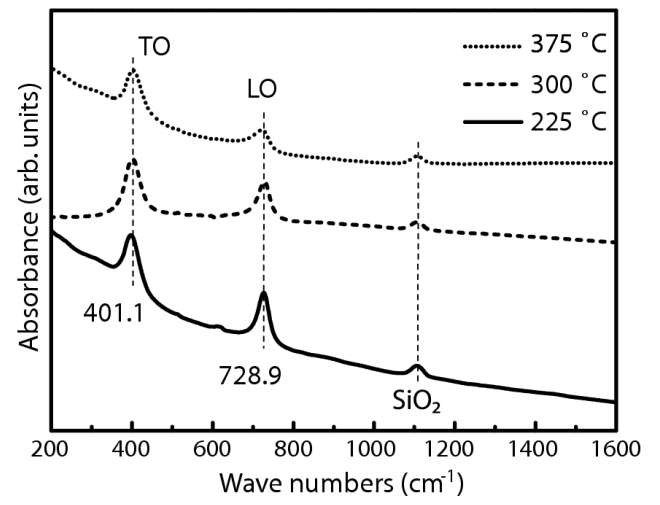

Fig. 5. FTIR spectrum at $\theta=70^{\circ}$ incident angle for the $\mathrm{MgO}$ films deposited by ALD at the indicated temperatures.

The FTIR spectra of the $\mathrm{MgO}$ films acquired at the grazing incidence angle $\left(\theta=70^{\circ}\right)$ are reported in Fig. 5. The $\mathrm{MgO}$ films deposited at $300^{\circ} \mathrm{C}$ and $375^{\circ} \mathrm{C}$ exhibit broad absorption bands corresponding to the TO mode at $401.1 \mathrm{~cm}^{-1}$, which is in good agreement with the wave number expected for single cubic MgO [17]. This TO mode appears at a slightly lower wave number $\left(\sim 398 \mathrm{~cm}^{-1}\right)$ for the film deposited at $225^{\circ} \mathrm{C}$. The phenomenon might be related to a residual amorphous component in the film. The additional absorption band at $\sim 728.9 \mathrm{~cm}^{-1}$ is related to the $\mathrm{LO}$ mode. The typical infrared absorption bands related to the $\mathrm{C}-\mathrm{O}$ and $\mathrm{C}-$ $\mathrm{H}$ stretching modes are not detectable, indicating negligible contaminations with organics in the as-prepared films.

\subsection{Full oxide approach by ALD to grow MTJ}

The results on the LSMO films composition given by the RBS measurements are shown in Table, together with the XRR results.

According to RBS measurements, the film grown at low temperature has a composition very close to the desired one $\left(\mathrm{La}_{0.7} \mathrm{Sr}_{0.3} \mathrm{MnO}_{3}\right.$. The film grown at $450^{\circ} \mathrm{C}$ is composed by two layers having different stoichiometry, as also confirmed by ToF-SIMS (not shown here) and XRR measurements. At higher temperatures the decomposition rate of the precursors is likely to change making the growth more difficult to control. There is also some Si content in this film, possibly due to the intermixing between the film and the substrate at high temperature.

Figure 6 shows the XRR spectra of the deposited LSMO films.

From the analysis of the XRR data (Fig. 6), it is apparent that the films grown at different temperatures are different in both thickness and roughness. The film grown at $T_{\mathrm{g}}=283^{\circ} \mathrm{C}$ is much smoother and thinner when compared to the one grown at $T_{\mathrm{g}}=450^{\circ} \mathrm{C}$. The critical edge $\left(q_{\mathrm{c}}\right)$ is $\sim 0.046$ and it is lower than the expected critical edge $\sim 0.049$ for the $\mathrm{La}_{0.7} \mathrm{Sr}_{0.3} \mathrm{MnO}_{3}$ compound. Correspondingly, the electronic density of our films is lower than that expected for the $\mathrm{La}_{0.7} \mathrm{Sr}_{0.3} \mathrm{MnO}_{3}$ perovskite type films. This could be partly explained by 
TABLE

RBS obtained composition and XRR fit parameters - film thickness $(t)$, critical edge $\left(q_{\mathrm{c}}\right)$, and surface roughness $(\sigma)$ for the LaSrMnO samples grown at $283^{\circ} \mathrm{C}$ and $450^{\circ} \mathrm{C}$.

\begin{tabular}{|c|c|c|c|c|}
\hline $\begin{array}{c}\text { Growth } \\
\text { temperature }\left({ }^{\circ} \mathrm{C}\right)\end{array}$ & \multirow{2}{*}{$\begin{array}{l}\text { Composition of the films } \\
\text { (RBS) } \\
\mathrm{La}_{0.7} \mathrm{Mn}_{1} \mathrm{Sr}_{0.3} \mathrm{MnO}_{3.8}\end{array}$} & \multicolumn{3}{|c|}{$\begin{array}{c}\text { Parameters obtained from the } \\
\text { XRR fit }\end{array}$} \\
\hline \multirow[b]{2}{*}{283} & & LaSrMnO & $\begin{array}{c}t(\AA) \\
q_{\mathrm{c}}\left(\AA^{-1}\right) \\
\sigma(\AA)\end{array}$ & $\begin{array}{c}350 \\
0.0465 \\
9 \\
\end{array}$ \\
\hline & & $\mathrm{SiO}_{2}$ & $\begin{array}{c}t \\
q_{\mathrm{c}} \\
\sigma\end{array}$ & $\begin{array}{c}83 \\
0.031 \\
4 \\
\end{array}$ \\
\hline \multirow{3}{*}{450} & \multirow{3}{*}{$\begin{array}{l}\mathrm{La}_{0.8} \mathrm{Mn}_{0.6} \mathrm{Sr}_{0.4} \mathrm{O}_{3}\left[\mathrm{Si}_{0.4}\right] \\
\mathrm{La}_{0.7} \mathrm{Mn}_{1.2} \mathrm{Sr}_{0.3} \mathrm{O}_{3}\left[\mathrm{Si}_{0.4}\right]\end{array}$} & LaSrMnO & $\begin{array}{c}t \\
q_{\mathrm{c}} \\
\sigma\end{array}$ & $\begin{array}{c}424 \\
0.045 \\
25 \\
\end{array}$ \\
\hline & & LaSrMnO & $\begin{array}{c}t \\
q_{\mathrm{c}} \\
\sigma\end{array}$ & $\begin{array}{c}417 \\
0.048 \\
71 \\
\end{array}$ \\
\hline & & $\mathrm{SiO}_{2}$ & $\begin{array}{c}t \\
q_{\mathrm{c}} \\
\sigma\end{array}$ & $\begin{array}{c}84 \\
0.031 \\
6\end{array}$ \\
\hline
\end{tabular}

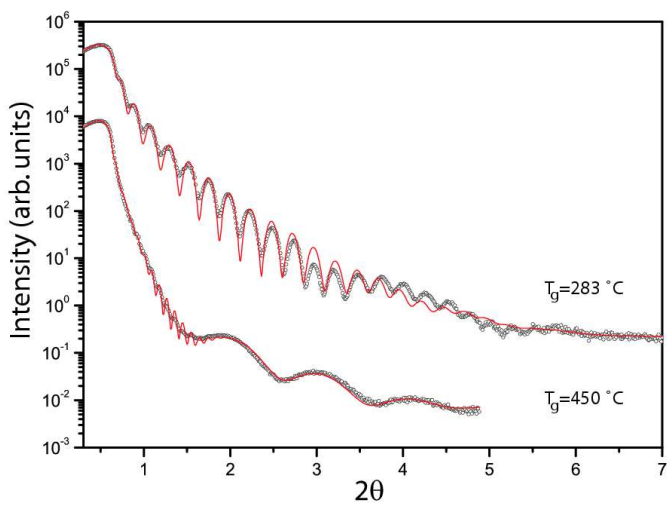

Fig. 6. XRR spectra of the LSMO films grown at different temperatures. The dots represent the experimental data and the lines are the simulations.

the fact that both films have a very low degree of crystallization and are mainly amorphous, as seen from the XRD measurements (not shown).

The preliminary results we have obtained in regard to the composition of the low temperature ALD grown LSMO film are very encouraging. We expect that by using good lattice-matched single crystal substrates we can improve the 
as-grown films crystallinity in the low temperature range $280-350^{\circ} \mathrm{C}$. Indeed, the magnetic and electrical properties of the manganites are very much affected by compositional and microstructural variations caused by stress or strain [18], and the deposition on to nearly lattice-matched substrates is most desirable. The deposition of LSMO films on $\mathrm{SrTiO}_{3}, \mathrm{LaAlO}_{3}$, and $\left(\mathrm{LaAlO}_{3}\right)_{0.3}\left(\mathrm{Sr}_{2} \mathrm{AlTaO}_{6}\right)_{0.7}$ substrates is in progress.

The realization of a full stack for MTJ will be pursued in the ALD system by subsequent deposition (without vacuum-break) of the $\mathrm{La}_{2} \mathrm{O}_{3}$ tunnel barrier and of a second LSMO electrode. This can be easily done due to the fact that we can use the same $\mathrm{La}\left(\mathrm{C}_{11} \mathrm{H}_{19} \mathrm{O}_{2}\right)_{3}$ precursor used in the growth of the quaternary perovskite films, combined with $\mathrm{O}_{3}$ to form the $\mathrm{La}_{2} \mathrm{O}_{3}$ films [19]. Alternatively, we will investigate the layers obtained from the $\mathrm{La}\left(\mathrm{C}_{5} \mathrm{H}_{5}\right)_{3}$ precursor combined with $\mathrm{O}_{3}$, in order to grow the $\mathrm{La}_{2} \mathrm{O}_{3}$ tunnel barrier [20].

\section{Conclusions}

We have presented the research effort to develop a full-ALD process for the fabrication of MTJ. Due to the difficulties in using ALD in depositing pure metals like Co without the use of hydrogen, we make use of a hybrid process where the two ferromagnetic electrodes, $\mathrm{Co}$ and $\mathrm{Fe}_{3} \mathrm{O}_{4}$, are deposited by a simple CVD set-up and the tunnel oxide is deposited by ALD. Preliminary results show that the $\mathrm{Fe}_{3} \mathrm{O}_{4} / \mathrm{MgO} / \mathrm{Co}$ could be a promising design structure for MTJ applications, due to the notable difference in the coercivity values of the FM electrodes. The hybrid process described here will introduce a simple and low cost method for the fabrication of MTJ and in general for the growth of FM layers for spintronics. We have reported the structural and compositional characterization of LSMO films deposited by ALD on $\mathrm{Si} / \mathrm{SiO}_{2}$ substrates. The first results we have obtained regarding the composition are very encouraging, and we expect that by using good lattice-matched single crystal substrates we can improve the as-grown film crystallinity. This will allow us to follow the full-oxide approach for the realization of MTJ using LSMO as FM electrodes and $\mathrm{La}_{2} \mathrm{O}_{3}$ as a tunnel barrier.

\section{Acknowledgments}

This work was partly supported by the CARIPLO foundation through the SOLARIS Project (2005-2007).

\section{References}

[1] S.S.P. Parkin, C. Kaiser, A. Panchula, P.M. Rice, B. Hughes, M. Samat, S. Yang, Nature Mat. 3, 862 (2004).

[2] S Yuasa, T. Nagahama, A. Fukushima, Y. Suzuki, K. Ando, Nature Mat. 3, 868 (2004).

[3] M. Ritala, M. Leskelä, in: Handbook of Thin Film Materials, Vol. 1, Ed. H.S. Nalwa, Academic Press, New York 2002, p. 135. 
[4] B.S. Lim, A. Rahtu, R.G. Gordon, Nature Mat. 2, 749 (2003), H. Kim, J. Vac. Sci. Technol. B 21, 2231 (2003).

[5] P. Seneor, A. Fert, J.L. Maurice, F. Montaigne, F. Petroff, A. Vaurés, Appl. Phys. Lett. 74, 4017 (1999).

[6] E. Dagotto, T. Hotta, A. Moreo, Phys. Rep. 344, 1 (2001).

[7] Yu Lu, X.W. Li, G.O. Gong, Gang Xiao, A. Gupta, P. Lecoeur, J.Z. Sun, Y.Y. Wang, V.P. Dravid, Phys. Rev. B 54, R8357 (1996).

[8] J.M. Coey, M. Viret, S. von Molnar, Adv. Phys. 48, 167 (1999).

[9] A.M. Haghiri-Gosnet, J.P. Renard, J. Phys. D, Appl. Phys. 36, R127 (2003).

[10] O. Nilsen, M. Lie, H. Fjellvag, A. Kjekshus, in: Rare Earth Oxide Thin Film: Growth, Characterization, and Applications, Eds. M. Fanciulli, G. Scarel, Springer Verlag, Heidelberg 2007.

[11] M.E. Gross, K. Schnoes Kranz, D. Brasen, H. Luftman, J. Vac. Sci. Technol. B 6, 1548 (1988).

[12] L. Zhou, P.E. Wigen, IEEE Trans. Magn. 29, 3052 (1993).

[13] C. Dallera, F. Fracassi, L. Braicovich, G. Scarel, C. Wiemer, M. Fanciulli, G. Pavia, B.C.C. Cowie, Appl. Phys. Lett. 89, 183521 (2006).

[14] S.D. Elliott, G. Scarel, C. Wiemer, M. Fanciulli, G. Pavia, Chem. Mater. 18, 3764 (2006).

[15] G. Scarel, S. Spiga, C. Wiemer, G. Tallarida, S. Ferrari, M. Fanciulli, Mater. Sci. Engineer. B 109, 11 (2004).

[16] M. Putkonen, T. Sajavaara, L. Niinistö, J. Mater. Chem. 10, 1857 (2000).

[17] J.R. Jasperse, A. Kahan, J.N. Plendl, Phys. Rev. 146, 526 (1966).

[18] C. Kwon, M.C. Robson, K.-C. Kim, J.Y. Gu, S.E. Lofland, S.M. Bhagat, Z. Trajanovic, M. Rajeswari, T. Venkatesan, A.R. Kratz, R.D. Gomez, R. Ramesh, J. Magn. Magn. Mater 172, 229 (1997).

[19] M. Nieminen, M. Putkonen, L. Niinistö, Appl. Surf. Sci. 174, 155 (2001).

[20] G. Scarel, A. Debernardi, D. Tsoutsou, S. Spiga, S.C. Capelli, L. Lamagna, S.N. Volkos, M. Alia, M. Fanciulli, unpublished. 